\title{
Seismic Behavior of Soft First Storey
}

\author{
${ }^{1}$ P.B.Lamb, ${ }^{2}$ Dr R.S. Londhe \\ ${ }^{1}$ PG Student Applied Mechanics Department, Government College of Engineering Aurangabad-431005 (M.S.) \\ India. \\ ${ }^{2}$ Asso. Professor of Applied Mechanics Department, Government college of Engineering Aurangabad -431005
} (M.S.) India,

\begin{abstract}
In the aftermath of recent North Kashmir Earthquake of October 8, 2005, there is increased awareness for the need to evaluate and improve the seismic performance of multistoried reinforced concrete buildings. There are several numbers of factors affecting the behavior of building. Stiffness irregularity in vertical direction is one of them, as a result of which soft storey is formed. In the dissertation work a parametric study is performed on multistoried building with soft first storey, located in seismic zone IV. It is intended to describe the performance characteristics such as stiffness, shear force, bending moment, drift. The study is carried out on a building with the help of different mathematical models considering various methods for improving the seismic performance of the building with soft first storey. Analytical models represent all existing components that influence the mass, strength, stiffness and deformability of structure. The equivalent static and multimodal dynamic analysis is carried out on the entire mathematical 3D model using the software SAP2000 and the comparisons of these models are presented. Finally, the performance of all the building models is observed in high seismic zone $V$.

Keywords: Soft storey, Problem, Parametric study, Earthquake Analysis, IS 1893:2002 provisions.
\end{abstract}

\section{Introduction}

Construction of multistoried buildings with open first storey is a common practice in India. This is an unavoidable feature and is generally adopted for parking of vehicles or reception lobbies. Such a building in which the upper stories have brick infill wall panel and open ground storey is called as stilt building and the open storey is called as stilt floor or soft storey. A soft storey also known as weak storey. It is a storey in a building that has substantially less resistance or stiffness than the stories above or below. A soft storey has inadequate shear resistance or inadequate ductility to resist the earthquake induced stresses. Such features are highly undesirable in buildings built in seismically active areas. The soft storey consists of discontinuity of strength stiffness which occurs the second storey connection. Soft storey concept has technical and functional advantages over the conventional construction. Becouse firstly, the reduction in spectral acceleration and base shear. Due to increase of natural period of the vibration of structure as in base isolated structure. Secondly, soft storey adopted for parking of vehicles and retail shopping, a large space for meeting room or a banking hall.

The Indian seismic code IS 1893:2002 (Clause no.4.20 on Page no.10) defines the soft storey as the "one in which the lateral stiffness is less than $\mathbf{7 0 \%}$ of that in the storey immediately above, or less than $80 \%$ of combined stiffness of three stories above."

\section{System Development}

The study is carried out on reinforced concrete moment resisting frame building with open first storey and unreinforced brick infill walls in the upper storeys. The building considered is the office building having G+6 stories, of which the ground storey is intended for parking. The building is kept symmetric in both orthogonal directions in plan to avoid the torsional response under pure lateral forces. Further the columns are taken to be Square to keep the discussion focused only on the soft first storey effect, without being distracted by the issue like orientation of columns. The plan dimension of the building is $22.5 \mathrm{~m}$ by $16 \mathrm{~m}$. Height of each storey is kept same as $3.1 \mathrm{~m}$. Other relevant data is tabulated in Table 3.1 .

Table 1: Analysis Data for Example Building

\begin{tabular}{|c|c|}
\hline Plan dimensions & $22.5 \mathrm{~m} \mathrm{X} 16 \mathrm{~m}$ \\
\hline Total height of building & $23.2 \mathrm{~m}$ \\
\hline Height of each storey & $3.10 \mathrm{~m}$ \\
\hline Height of parapet & $1.00 \mathrm{~m}$ \\
\hline Depth of foundation & $1.50 \mathrm{~m}$ \\
\hline Size of longitudinal beams & $300 \mathrm{mmX} 500 \mathrm{~mm}$ \\
\hline Size of transverse beams & $300 \mathrm{mmX} 450 \mathrm{~mm}$ \\
\hline
\end{tabular}


Seismic Behavior Of Soft First Storey

\begin{tabular}{|c|c|} 
Size of columns & $500 \mathrm{mmX} 500 \mathrm{~mm}$ \\
\hline Thickness of slab & $120 \mathrm{~mm}$ \\
\hline Thickness of external walls & $230 \mathrm{~mm}$ \\
\hline Thickness of internal walls & $115 \mathrm{~mm}$ \\
\hline Seismic zone & IV \\
\hline Soil condition & Hard soil \\
\hline Response reduction factor & 1 \\
\hline Importance factor & $1.875 \mathrm{kN} / \mathrm{m}^{2}$ \\
\hline Floor finishes & $2.0 \mathrm{kN} / \mathrm{m}^{2}$ \\
\hline Live load at roof level & $5.0 \mathrm{kN} / \mathrm{m}^{2}$ \\
\hline Live load at all floors & $\mathrm{M} 20$ \\
\hline Grade of Concrete & $\mathrm{Fe} 415$ \\
\hline Grade of Steel & $25 \mathrm{kN} / \mathrm{m}^{3}$ \\
\hline Density of Concrete & $20 \mathrm{kN} / \mathrm{m}^{3}$ \\
\hline Density of brick masonry &
\end{tabular}

\section{Modeling of Building:}

The building is modeled using the finite element software SAP 2000. The analytical models of the building include all components that influence the mass, strength, stiffness and deformability of structure. The building structural system consists of beams, columns, slab, walls, and foundation. The non structural elements that do not significantly influence the building behavior are not modeled. Beams and columns are modeled as two noded beam elements with six DOF at each node. The floor slabs are assumed to act as diaphragms, which insure integral action of all the vertical load resisting elements and are modeled as four noded shell element with six DOF at each node. Walls are modeled by equivalent strut approach and wall load is uniformly distributed over beams. The diagonal length of the strut is same as the brick wall diagonal length with the same thickness of strut as brick wall, only width of strut is derived. Walls are considered to be rigidly connected to the columns and beams. In the modeling, material is considered as an isotropic material and following designations are used for various models.

\begin{tabular}{|c|c|}
\hline Model I & Building with Uniform Infill in all Storeys \\
\hline Model II & Building with Open First Storey \\
\hline Model III & Open First Storey with Walls at Specific Location in First Storey \\
\hline Model IV & Open First Storey with Cross Bracings \\
\hline Model V & Open First Storey with Stiffer Columns \\
\hline Model VI & Open First Storey with Shear Walls \\
\hline Model VII & Open First Storey with Tapered Forms of Columns \\
\hline Model VIII & Open First Storey with Light Weight Infill in the Upper Storey's \\
\hline
\end{tabular}

The 3D building model generated in SAP2000 is shown in figure.

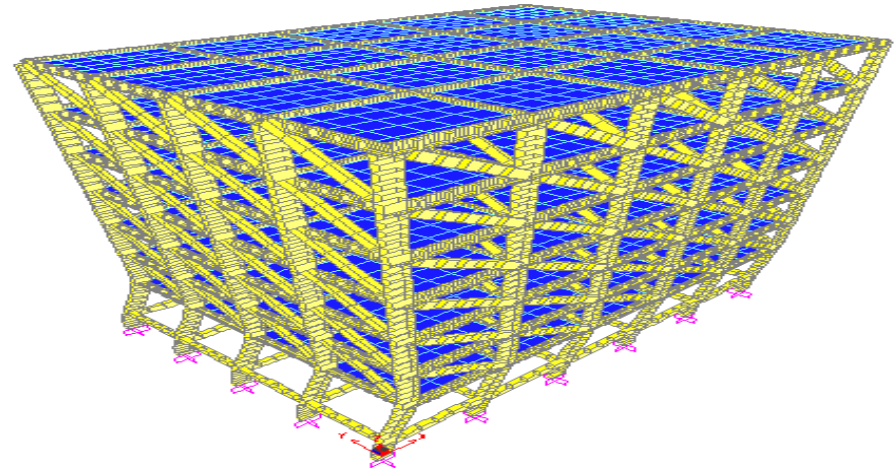

III. Results And Discussion

\section{Lateral Displacement:}

A graph is plotted taking floor level as the abscissa and the displacement as the ordinate for different models in the transverse and longitudinal direction as shown in Figure 1 and Figure 2. From the above displacement profiles it is observed that large displacement occurs in case of soft storey building (model II). On the other hand if there is uniform infill in all the storeys (model I), the displacements are very small in the first storey. It is seen that the use of infill at selected locations in the first storey reduces the displacement up to $34 \%$ as compared with model II. Cross bracing (Model IV) reduces the displacement to 54\% of model II. Stiffer 
column (Model V) reduces the displacement to 70\%. By introducing the shear wall (Model VI) reduces the displacement to $80 \%$ of model II. There is not much reduction in the displacements at first floor, if we provide the tapered column or light weight materials but they certainly reduce the stiffness irregularity

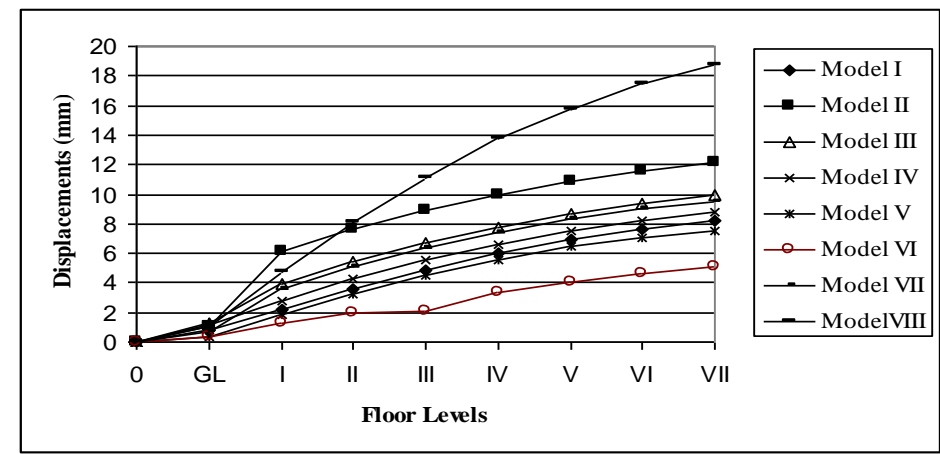

Figure 1: Displacement Profile in Longitudinal Direction for Zone IV (ESA)

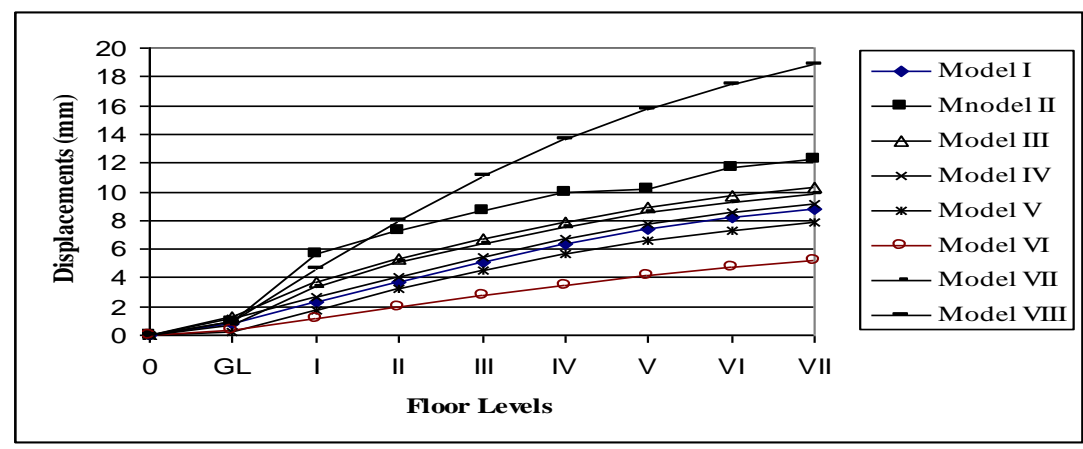

Figure 2: Displacement Profile in Transverse Direction For Zone IV (ESA)

\section{Storey Drift:}

A graph is plotted taking floor level as the abscissa and the storey drift as the ordinate for different models in the transverse and longitudinal direction as shown in Figure 2 and Figure 3.

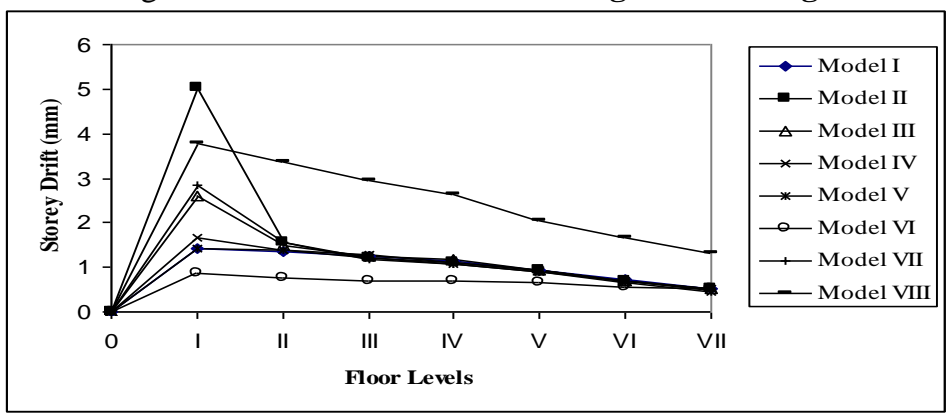

Figure 2: Storey Drift Profile in Longitudinal Direction for Zone IV (ESA)

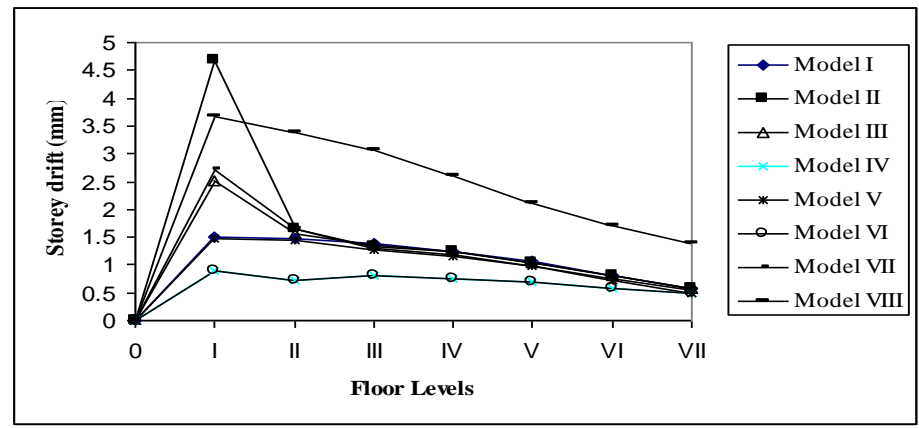

Figure 3: Storey Drift Profile in Transverse Direction for Zone IV (ESA)

An abrupt change in displacement profile indicates the stiffness irregularity. There is sudden change in the slope at first storey. The graph shows the storey drift is maximum for Model II, this indicate ductility 
demand in the first storey column for this model is largest. However the storey drift profile becomes smoother right from III to model VI indicating large stiffness and less ductility demand. The use of tapered form of the columns also reduces the storey drift at first floor level. It is seen that in case of model VIII the storey drift at first floor is large as that of model II but there is no abrupt change in the slope, shown by the smooth curve.

\section{Bending Moment and Shear Force in Columns:}

The maximum bending moments in the columns in longitudinal and transverse direction are shown in Figure 4 and Figure 5.

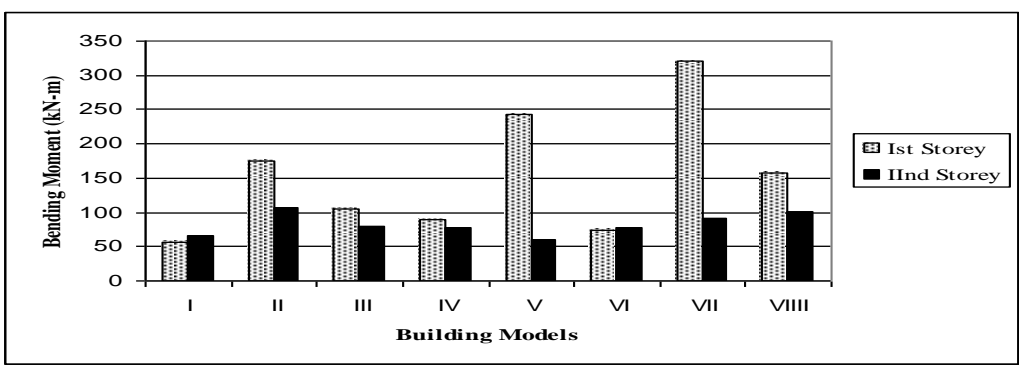

Figure 4: Comparison of Maximum Bending Moment in Longitudinal Direction for Zone IV (ESA)

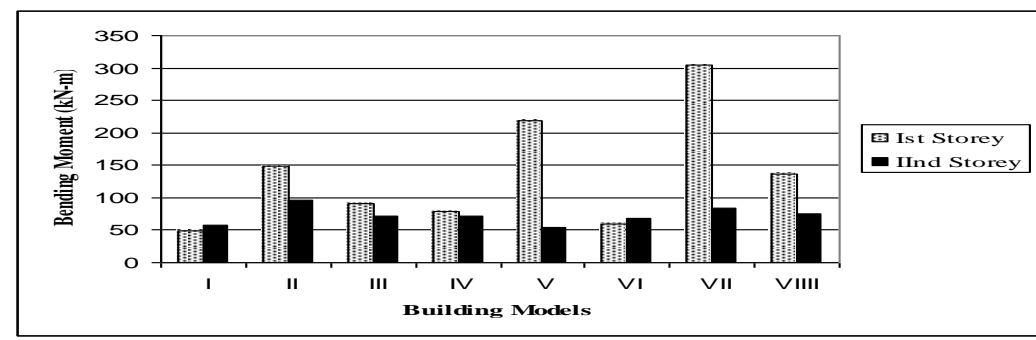

Figure 5: Comparison of Maximum Bending Moment in Transverse Direction for Zone IV (ESA) 6 and Figure 7.

The maximum shear forces in the columns in longitudinal and transverse direction are shown in Figure

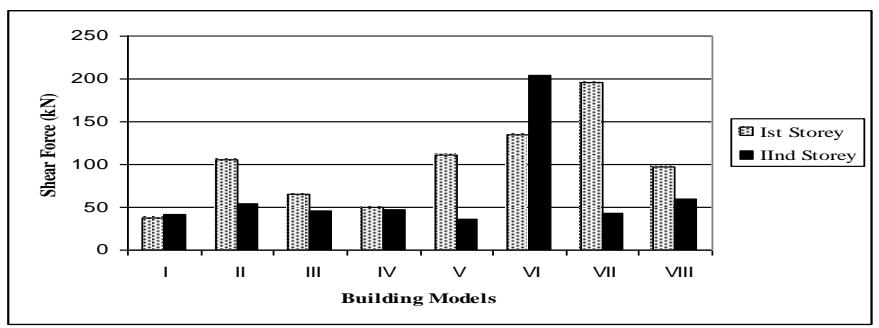

Figure 6: Comparison of Maximum Shear Force in Longitudinal Direction for Zone IV (ESA)

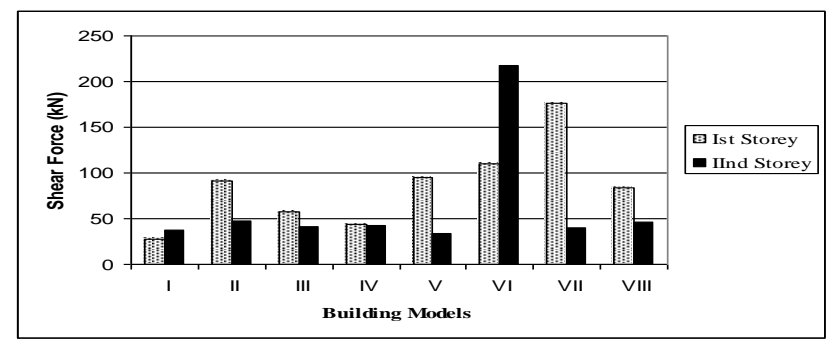

Figure 7: Comparison of Maximum Shear Force in Transverse Direction for Zone IV (ESA)

The bending moment and shear force demands are severely higher for first storey column in case of soft first storey buildings (Model II). The bending moment is quite large in the first storey columns as compared to the upper storeys. Shear wall (Model VI) is found to be very effective in reducing the bending moment in the columns, as the force is distributed in proportion to the stiffness of the members. In Model IV and Model VI the moments are reduced by 50-60\% as compared to soft storey models and the bending moment difference between the first and upper storeys is also less. From strength point of view the performance of these models are better. The use of brick infill wall or light weight infill wall (model III and VIII) are not very effective in 
reducing the strength demand on first storey column. From the above observations, it is seen that the higher size of columns (Model V and VII) is effective in reducing the drift. But it increases the shear force and bending moment in the first storey. By increasing stiffness of column, displacement of column decreases and its shear force and bending moment increases.

Base Shear: The base shear for different building models in both the directions is shown in Figure 8.

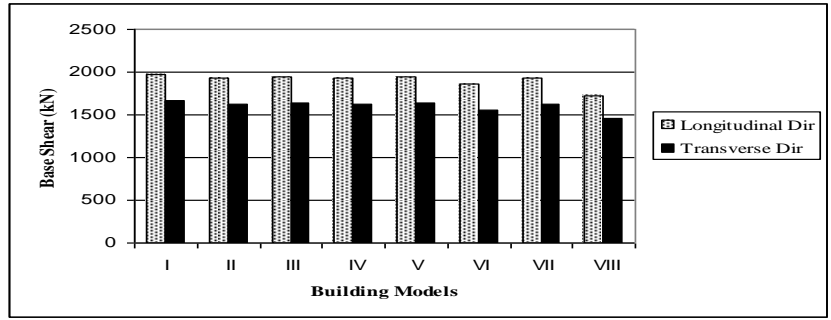

Figure 8: Base Shear in Longitudinal and Transverse Direction for Zone IV (ESA)

Base shear of all the above models are fairly constant except model VIII in which it is reduced to $10 \%$ of model II because of use of light weight material infill in the upper storeys.

\section{Time Period and Frequency:}

A graph is plotted taking modes on the $\mathrm{X}$ axis and time period in second on $\mathrm{Y}$ axis for all the building models as shown in the Figure 9.

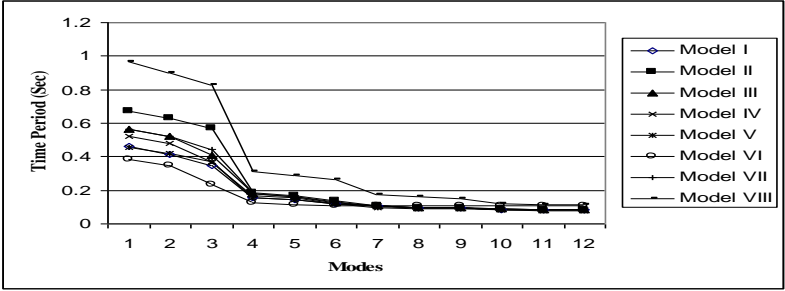

Figure 9: Comparison of Time Period for Different Modes in Zone IV

It is observed that the time period of vibration is more for models II and VIII While it is considerably reduced for models III, IV, V, VI and VII. Period of vibration is found to be minimum for model V and VI.

\section{Conclusion}

1. Shear wall and cross bracings are found to be very effective in reducing the stiffness irregularity and bending moment in the columns. Higher size of columns (stiffer and tapered form) is effective in reducing the drift, but it increases the shear force and bending moment in the first storey. Lightweight infill is found to be very effective in reducing the stiffness irregularity and storey drift.

2. The use of masonry infill is found to be not effective in reducing the strength demand on the first storey columns, though they considerably reduce the stiffness irregularity. In this case the stiffness of first storey is $45 \%$ of second storey stiffness.

3. The use of cross bracings significantly increases the first storey stiffness. The first storey stiffness comes out to be $70 \%$ of second storey stiffness. It considerably reduces the lateral displacement and shows the smooth drift profile. The use of cross bracings reduces the moments by 50-60\% as compared to soft storey model.

4. Stiffer columns are effective in reducing the stiffness irregularity and drift, but there is increase in the shear force and bending moment in the first storey. Higher size columns increase the stiffness up to $73 \%$ and do not shows abrupt change in the displacement profile.

5. Shear walls are found to be most effective in reducing the stiffness irregularity, storey drift and strength demand in the first storey. When shear walls are introduced the stiffness of first storey increased to $80 \%$ and moments are reduced by $50-60 \%$.

6. The tapered form of columns helps in reducing the storey drift but it increases the forces in the columns. In this case the induced torsion is significantly higher than soft storey model.

7. Light weight infill is found to be quite effective in increasing the stiffness of first storey ( $88 \%$ of second storey stiffness), storey drift and marginally reduces the strength demand in first storey columns

8. When the results from equivalent static analysis are compared with response spectrum analysis, it is observed that the lateral displacements and inter storey drift comes out to be $5-25 \%$ less for RSA as compared with ESA. Shear force and bending moments are found to be 10-30\% less for response spectrum analysis. However, the axial forces are fairly same for two methods. 
9. Though there is increase in the displacements and forces in the zone V as compared to zone IV, these measures considerably decreases the storey drift and stiffness irregularity in zone $\mathrm{V}$ and hence there performance is fairly good in this zone.

\section{References}

[1] Dasgupta, K. and Murty, C. V. R., "Quantitative Seismic Retrofitting of Open Ground Storey RC Frame Buildings", Workshop on Retrofitting of Structures, Oct 10- 11, 2003, IIT Roorkee, pp. 186-192.

[2] Arlekar, J. N., Jain, S.K. and Murty, C. V. R., "Seismic Response of RC Frame Building with Soft First Storey", Proceedings of CBRI Golden Jubilee Conference on Natural Hazards in Urban Habitat, 1997, New Delhi, pp. 13-24.

[3] Christopher, A., "Soft First Storeys: Truths and Myths", Eighth World Conference on Earthquake Engineering California, Vol V, pp. 943-950.

[4] Kumar, S. R. and Kumar, G. R., "Seismic Retrofit of Soft-Storey Building Using Steel Bracing", Workshop on retrofitting of structures, Oct 10-11, 2003, IIT Roorkee, pp. 148-158.

[5] Kabeyasawa, T., Sanada, Y. and Kuramoto, H., "Design and Analysis of a Six- Storey RC Frame-Wall System with Soft First Storey for Shaking Table Test", Vol. 35, No. 11, 2006, pp. 1425-1451.

[6] Singh, Y., Paul, D. K. and Mehdi, S. Z., "Seismic Safety of Stilt Buildings", Proceedings of Twelfth Symposium on Earthquake Engineering, Roorkee, December 2002, pp. 918-925.

[7] Garcia, L. D., "Tri-Center Field Mission 2002; Taiwan”, Department of Civil Structural and Environmental Engineering University at Buffalo.2002, pp. 127-133.

[8] Yong, L., Tassios, T. P. and Zhang, G. F., Vintzileou, E., "Seismic Response of Concrete Frames with Strength and Stiffness Irregularities", ACI Structural Journal Title no.96-S24, Vol. 96, No. 2, March April 1999, pp.221-229.

[9] Kara, M. E. and Altin, S., "Behavior of Reinforced Concrete Frames with Reinforced Concrete Partial Infills", ACI Structural journal Title no. 103-S72, Vol. 103, No .5, September-October 2006, pp. 701-709.

[10] Canbay, E., Ersoy, U. and Ozcebe, G., "Contribution of Reinforced Concrete Infill to Seismic Behavior of Structural Systems", ACI Structural Journal Title no. 100-S66, Vol. 100, No. 5, September-October 2003, pp. 637-643.

[11] Binici, B. and Ozcebe, G., "Analysis Method for Seismic Evolution of Reinforced Concrete Frames Strengthened with FRPS", Department of Civil Engineering Ankara, Turkey, 2005, pp. 45-52. 